\title{
INFLUENCE OF IONIZING RADIATION ON THE CORROSION RESISTANCE OF ZnNi/SiO 2 COMPOSITE COATINGS
}

\author{
D. V. Lavysh, ${ }^{\text {a }}$ N. G. Val'ko, ${ }^{a}$ V. M. Anishchik, \\ R. R. Korennoi, ${ }^{a}$ and Milan Šebok
}

UDC 541.15

The influence of $x$-ray radiation on the protective properties of $\mathrm{ZnNi} / \mathrm{SiO}_{2}$ composite coatings has been investigated experimentally, and the optimal regimes of their electrodeposition on irradiation by the method of complete factor experiment have been revealed. It is shown that the action of x-ray radiation on the electrolytes used for electrodeposition of $\mathrm{ZnNi} / \mathrm{SiO}_{2}$ leads to an increase in their dispersive power, which makes it possible to form composite coatings with the metal uniformly distributed over the surface and, correspondingly, with elevated corrosion resistance. It has been found that the action of $x$-ray radiation on the process of electric deposition of

$\mathrm{ZnNi} / \mathrm{SiO}_{2}$ coatings promotes formation of layers with enhanced anticorrosion properties. Based on experimental data and according to the method of complete factor experiment, the influence of variations in the $x$-ray radiation exposure dose power and concentration of $\mathrm{SiO}_{2}$ nanoparticles in the electrolyte on the dispersive power of electrolytes and corrosion resistance of $\mathrm{ZnNi} / \mathrm{SiO}_{2}$ coatings has been considered. Regression equations have been obtained, an analysis of the coefficients of which allowed the conclusion that a maximum increase in the dispersive power and a decrease in the rate of appearance of corrosion products on $\mathrm{ZnNi} / \mathrm{SiO}_{2}$ coatings are achieved on combination of two factors: addition of $\mathrm{SiO}_{2}$ nanoparticles to the electrolyte and irradiation of the electrolyte by $x$-ray radiation in the process of coating deposition. The developed statistical model allows one to adequately determine the optimal concentrations of $\mathrm{SiO}_{2}$ nanoparticles in an electrolyte and the regime of $x$-ray irradiation for obtaining coatings with enhanced anticorrosive properties.

Keywords: electrocrystallization, x-ray radiation, current efficiency, regression equations, factor, criteria, adequacy.

Introduction. At the present time, the methods of electrochemical deposition occupy the most important place in protecting metals form corrosion, which is explained by their such substantial advantages over other methods as the simplicity of the process and relatively inexpensive equipment. Development of electrochemical methods of protection against corrosion presupposes modernization of the available optimal regimes of electrodeposition of protective coatings or development of new ones with the aim of forming layers with needed performance characteristics.

To solve the problems of protecting metals and metalwork against corrosion for the purpose of increasing their service life in corrosive media, it is important to improve the technological processes of obtaining coatings and, in particular, those based on zinc. These coatings owe their protective properties to the fact that the electrochemical potential of zinc is much smaller for ferrous metals and, as a consequence, the protection by zinc-containing coatings is achieved by electrochemical means. Taking into account that zinc-based electroplating is widely used in industry, of particular importance is the development of new methods of improving the quality of their surfaces and of their physicomechanical properties. It was shown previously that the use of ionizing radiation, $\mathrm{x}$-rays in particular, in the course of forming coatings allows one to obtain coatings with improved service characteristics and a strengthened surface layer [1]. It should be noted that obtaining composite coatings from electrolytes is somewhat hampered, since in the process of electrodeposition a hardly soluble film is formed and adsorbed on the cathode surface from the products of intermediate zinc reduction that inhibits the inclusion of particles of the second phase [2]. The method of action of $\mathrm{x}$-ray radiation on the electrochemical system in the process of deposition of composite coatings prevents the adsorption of oxide and hydroxide films on the substrate surface. Under the influence of $\mathrm{x}$-ray radiation, due to the radiolysis, active radicals originate in the electrolyte that favor the natural mixing of

\footnotetext{
${ }^{\mathrm{a}}$ Ya. Kupala State University of Grodno, 22 Ozheshko Str., Grodno, 230023, Belarus; email: nvalko@gmail.com; b Belarusian State University, 4 Nezavisimost' Ave., Minsk, 220030, Belarus; email: Anishchik@bsu.by; Zhilina University, 8215/1 Universitna Str., Zhilina, Slovakia; email: milan.sebok@fel.uniza.sk. Translated from InzhenernoFizicheskii Zhurnal, Vol. 94, No. 3, pp. 653-657, May-June, 2021. Original article submitted February 14, 2020.
} 
the solution and intensify the process of electrodeposition [3]. It should also be taken into account that radiative-chemical conversions occurring in electrolytes under irradiation lead to a change in the microstructure of the produced deposits, which can modify their service characteristics [4].

Since the main concern of the majority of works dealing with the development of the technological process of electrodeposition of zinc coatings is the solution of problems associated with the optimization of the quality of coatings, regimes and conditions of producing them, particularly important is the use of modern mathematical methods of planning and analysis of the experiment. Therefore the purpose of the work was experimental investigation of the effect of $\mathrm{x}$-ray radiation on the protective properties of $\mathrm{ZnNi} / \mathrm{SiO}_{2}$ composite coatings, as well as the clarification of the optimal regimes of electrodeposition of protective $\mathrm{ZnNi} / \mathrm{SiO}_{2}$ coatings with needed service characteristics by the method of complete factor experiment.

Investigative Techniques. Composite $\mathrm{ZnNi} / \mathrm{SiO}_{2}$ coatings were deposited from faintly acid electrolytes containing $\mathrm{SiO}_{2}$ nanoparticles: 1 and $0.1 \mathrm{~g} / \mathrm{L}$. Electrodeposition was run at the temperature of thermostatic control of electrolytic cell equal to $21^{\mathrm{O}} \mathrm{C}$. The electrolytic cell was irradiated with $\mathrm{x}$-rays directly in the process of electrodeposition. A voltage of $50 \mathrm{kV}$ and current of $15 \mathrm{~mA}$ were supplied to a molybdenum-anode $\mathrm{x}$-ray tube. The qualitative estimation of the x-ray irradiation dose for $1 \mathrm{~h}$ amounted to $100 \mathrm{kR} / \mathrm{h}$.

The dispersive power (DP) was determined with the aid of the Moler's slit cell according to the State Standard GOST 9.309 [5]. As the electrodes in the cathode block of the slit cell we used indifferent aluminum cathodes that do not interact with electrolytes without an electric current passing through them.

The corrosion resistance of coatings was investigated by the method of alternate immersion of samples into an electrolyte according to the State Standard GOST 9.308 [6], the essence of which is that the corrosion process is accelerated by alternating immersions of samples into an electrolyte with their drying in the air. As the electrolyte we used a solution of sodium chloride of concentration $30 \pm 3 \mathrm{~g} / \mathrm{L}$. The solution was replaced every 15 days of carrying out tests. The degree of corrosion injury with rust was estimated by the method of stencilling [6].

Experimental Results. The results of investigation of the dispersive power of the electrolytes used for electrodeposition of a $\mathrm{ZnNi}$ alloy and $\mathrm{ZnNi} / \mathrm{SiO}_{2}$ composite coatings are presented in Fig. 1. It should be noted that a faintly acid electrolyte has a rather low value of dispersive power due to the fact that the discharge of metal ions in the electrolyte of this composition occurs at the cost of simple hydrated ions. On addition of $\mathrm{SiO}_{2}$ nanoparticles to the electrolyte in the amount of 1 and $0.1 \mathrm{~g} / \mathrm{L}$, the value of the dispersive power decreases insignificantly (within the limits of error).

It has been revealed that the x-ray radiation acting on an electrolyte in the course of electrodeposition leads to an increase in the dispersive power of all of the electrolytes studied. Thus, the dispersive power of the faintly acid electrolyte used for deposition of $\mathrm{ZnNi}$ on $\mathrm{x}$-ray irradiation increases by $30 \%$, for electrolytes with $\mathrm{SiO}_{2}$ nanoparticles $(0.1 \mathrm{~g} / \mathrm{L})$, by $42 \%$, and for electrolytes with $\mathrm{SiO}_{2}$ nanoparticles in the amount of $1 \mathrm{~g} / \mathrm{L}$ the dispersive power increases more than twice. The increase in the dispersive power on irradiation is caused by the appearance of a large number of active radical particles due to the radiolysis of electrolytes on irradiation and corresponding increase in their electric conductivity. The increase in the effective electric conductivity leads to a uniform distribution of current over the cathode height, and to an increase in the dispersive power of electrolyte. It should be noted that the appearance of the primary products of radiolysis and in the first place of $\mathrm{H}^{+}$promotes a decrease in the evolvement of molecular hydrogen on the cathode whose bubbles prevent the deposition of the alloy. This indicates that in the coatings obtained on irradiation the number of pores will decrease, and the metal will be distributed more uniformly over the cathode surface. Thus, the increase in the dispersive power of irradiated electrolytes and the corresponding distribution of the current over the cathode height due to the increase in the effective electric conductivity and the decrease in the filling with gas must lead to electric deposition of $\mathrm{ZnNi} / \mathrm{SiO}_{2}$ coatings with enhanced protective properties.

Figure 2 presents the results of investigation of the corrosion resistance of $\mathrm{ZnNi}$ and $\mathrm{ZnNi} / \mathrm{SiO}_{2}$ coatings with the concentration of $\mathrm{SiO}_{2}$ nanoparticles in the electrolyte in the amount of 1 and $0.1 \mathrm{~g} / \mathrm{L}$. The object of observation was the period of time up to the appearance of rust on the substrate - a visible product of corrosion. It is seen from the figure that the rust on the $\mathrm{ZnNi}$ coating appears only in $72 \mathrm{~h}$. Such significant corrosion resistance of these coatings is associated with the presence of the high content of zinc in them (more than 90\%) [4] which protects the metal by forming a thin oxide film on the coating that prevents the penetration of oxygen inside the zinc. In corroding a coating, the formed oxides have a volume greater than that of the primary metal, and therefore their film breaks immediately, becomes spongy, and transmits oxygen to the unoxidized material, which leads to the destruction of the metal and to the appearance of rust. It is also seen from Fig. 2 that addition of nanoparticles to the electrolyte for deposition of $\mathrm{ZnNi}$ coatings favors an increase in the corrosion resistance 


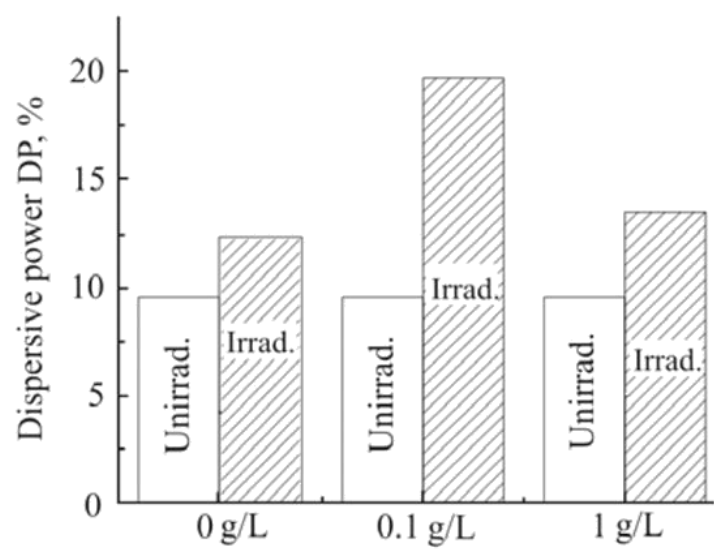

Concentration of $\mathrm{SiO}_{2}$ nanoparticles in the electrolyte

Fig. 1. Dispersive power of electrolytes with $\mathrm{SiO}_{2}$ nanoparticles $(0,0.1$, and $1 \mathrm{~g} / \mathrm{L})$ in the $\mathrm{x}$-ray radiation field (irradiated) and without irradiation (unirradiated).

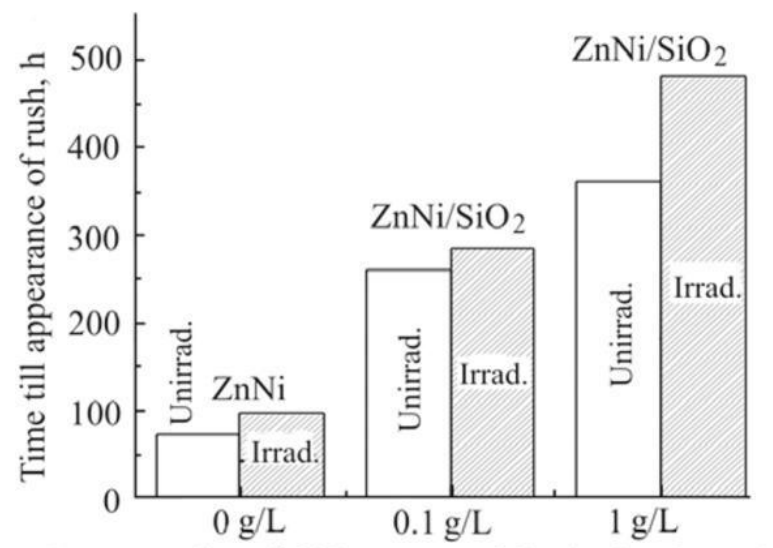

Concentration of $\mathrm{SiO}_{2}$ nanoparticles in the electrolyte

Fig. 2. Corrosion resistance of $\mathrm{ZnNi}$ and $\mathrm{SiO}_{2}$ coatings with concentration of $\mathrm{SiO}_{2}$ nanoparticles in the electrolyte in the amount of 1 and $0.1 \mathrm{~g} / \mathrm{L}$, formed in the field of $\mathrm{x}$ ray radiation.

against the $3 \%$ solution of $\mathrm{NaCl}$. So, the products of rust on $\mathrm{ZnNi} / \mathrm{SiO}_{2}$ composite coatings deposited from electrolytes with a concentration of nanoparticles of $0.1 \mathrm{~g} / \mathrm{L}$ appear only in $240 \mathrm{~h}$. An increase in the concentration of nanoparticles up to $1 \mathrm{~g} / \mathrm{L}$ leads to the increase in the time of the appearance of rust on the surface of $\mathrm{ZnNi} / \mathrm{SiO}_{2}$ coatings to $320 \mathrm{~h}$.

It has been found that the action of the $\mathrm{x}$-ray radiation in the process of the formation of coatings leads to an increase in the interval of time before the appearance of rust on coatings. Thus, for $\mathrm{ZnNi}$ coatings, this time increases to 92 $\mathrm{h}$, and for $\mathrm{ZnNi} / \mathrm{SiO}_{2}$ coatings deposited from electrolytes with concentration of nanoparticles of $1 \mathrm{~g} / \mathrm{L}$, to $480 \mathrm{~h}$. The data obtained correlates with the results of investigation of the dispersive power of electrolytes: the increase in the dispersive power of irradiated electrolytes leads to the formation of $\mathrm{ZnNi} / \mathrm{SiO}_{2}$ coatings with enhanced protective properties.

For developing a mathematical model that would account for the influence of the variations of the x-ray irradiation dose power and of the concentration of $\mathrm{SiO}_{2}$ nanoparticles in the electrolyte on the dispersive power of the electrolyte and corrosion stability of $\mathrm{ZnNi} / \mathrm{SiO}_{2}$ coatings, respectively, using the experimental data we composed the matrix of planning variable factors (power of the x-ray irradiation dose, concentration of $\mathrm{SiO}_{2}$ nanoparticles), which were coded by dimensionless quantities -1 and +1 in accordance with the value of the factor (Table 1) [7,8]. As the output parameter we considered the dispersive power of electrolytes and the time till the appearance of red corrosion. The statistical models of the object of investigation were the response functions (the dispersive power of electrolytes and the time till the appearance of red corrosion) that connect the output data with the factors $\left(P_{\exp },\left[\mathrm{SiO}_{2}\right]\right)$ that varied in the course of experiments. 
TABLE 1. Planning Matrix

\begin{tabular}{|c|c|c|c|c|c|c|c|}
\hline$x_{1}$ & $x_{2}$ & \multicolumn{7}{c|}{ Results of experiment } & $y$ \\
\hline \multicolumn{8}{|c|}{ Dispersive power DP, \% } \\
\hline-1 & -1 & 8 & 11 & 12 & 10 & 10 & 10.2 \\
-1 & 11 & 11 & 10 & 14 & 12 & 12 & 11.8 \\
11 & -1 & 7 & 9 & 11 & 10 & 9 & 9.2 \\
11 & 11 & 18 & 19 & 23 & 20 & 20 & 20 \\
\hline \multicolumn{7}{|c|}{ Time till appearance of red corrosion, $t_{\text {cor.r }}$ h } \\
\hline-1 & -1 & 70 & 72 & 73 & 71 & 74 & 72 \\
-1 & 11 & 104 & 99 & 85 & 96 & 95 & 95.8 \\
11 & -1 & 368 & 354 & 358 & 362 & 361 & 360.6 \\
11 & 11 & 484 & 476 & 480 & 485 & 476 & 480.2 \\
\hline
\end{tabular}

TABLE 2. Values of Coefficients of Factors

\begin{tabular}{|c|c|c|}
\hline Coefficients & Values of coefficients DP, \% & $\begin{array}{c}\text { Values of coefficients for the time of } \\
\text { appearance of red corrosion, } \mathrm{h}\end{array}$ \\
\hline b0 & 12.8 & 345.8 \\
b1 & 1.8 & 74.6 \\
b2 & 3.1 & 35.3 \\
b12 & 2.3 & 24.5 \\
Deviation of coefficient $S_{\text {coef }}$ & 0.35 & 1.44 \\
Mean square deviation $S_{y}{ }^{2}$ & 2.525 & 41.7 \\
Residua dispersion $S_{\text {res }}^{2}$ & 5.05 & $1.29 \cdot 10^{-26}$ \\
Fisher number $F_{\text {calc }}$ & 2 & $2 \cdot 10^{-29}$ \\
\hline
\end{tabular}

In checking the hypothesis on the uniformity of dispersions, we calculated the values of the Fisher criterion, Student's critical values and coefficients, mean square deviations of the dispersion of reproducibility, as well as the residual reproducibility $[9,10]$. The values of the coefficients and mean square deviations calculated by Student's $t$ criterion are presented in Table 2. The results of comparison of the calculated coefficients with critical values have shown that all the coefficients are significant.

The regression equations for the dispersive power of electrolytes under $\mathrm{x}$-ray irradiation and the time of appearance of corrosion products on the metal protected by a composite coating in absolute values have the form

$$
\begin{aligned}
& \mathrm{DP}=12.8+\underset{1}{(z-0.5) 3.6+\frac{z^{-} z-50}{50}} 3.1+4.6\left(z_{1}-0.5\right) \frac{z_{2}-50}{50} \text {, } \\
& t_{\text {cor.r }}=345.8+149.2+(z-0.45)+\frac{z_{2}-50}{50} 33+49\left(z_{1}-0.45\right) \frac{z_{2}-50}{50},
\end{aligned}
$$

where $z_{1}$ is the concentration, $z_{2}$ is the irradiation intensity.

It is possible to conclude from the regression equation (1) that a maximum increase in the dispersive power of electrolytes for crude nickel plating can be achieved by adding nanoparticles to the electrolyte and simultaneously using the 
$\mathrm{x}$-ray radiation, i.e., the case at hand is that the joint effect of two key factors (the concentration of nanoparticles and power of the X-ray radiation dose) is much stronger than of each separate factor. The regression equation (2) shows that the factor showing the high corrosion resistance in the scale studied is the concentration of nanoparticles. It is much higher than the power of the $\mathrm{x}$-ray radiation dose, whereas the joint influence of the initial factors is the least.

\section{CONCLUSIONS}

1. The results of experimental investigation of the influence of x-ray radiation acting on the electrolyte in the process of forming protective $\mathrm{ZnNi} / \mathrm{SiO}_{2}$ coatings on their corrosion resistance are presented. The laws governing the decrease in the speed of appearance of rust products with increase in the concentration of $\mathrm{SiO}_{2}$ nanoparticles in the electrolyte have been revealed. It is shown that the action of the $\mathrm{x}$-ray radiation in the process of formation of $\mathrm{ZnNi} / \mathrm{SiO}_{2}$ coatings leads to an increase in the period of time up to the appearance of rust on coatings, which is associated with the increasing dispersive power of an electrolyte under irradiation and formation of dense coatings with the metal uniformly distributed over the cathode.

2. Based on experimental data with the use of the method of complete factor experiment, a mathematical model has been developed that accounts for the influence of the varying power of the x-ray radiation dose and concentration of $\mathrm{SiO}_{2}$ nanoparticles in the electrolyte on the dispersive power of electrolytes and corrosion resistance of $\mathrm{ZnNi} / \mathrm{SiO}_{2}$ coatings, respectively. The model developed allows one to adequately determine the optimal concentration of $\mathrm{SiO}_{2}$ nanoparticles in the electrolyte and the regime of irradiation by $\mathrm{x}$-rays for obtaining coatings with enhanced anticorrosion properties at the given value of the dispersive power of the electrolyte.

\section{REFERENCES}

1. N. Valko, A. Kasperovich, and T. N. Koltunowicz, Forming a structure of the CoNiFe by X-ray irradiation, Funct. Mater. Lett., 11, No. 2, 1850044 (2018).

2. E. V. Proskurkin, V. A. Popovich, and A. T. Moroz, Galvanizing [in Russian], Metallurgiya, Moscow (1988).

3. A. Pikaev, Modern Radiation Chemistry. Radiolysis of Gases and Liquids [in Russian], Nauka, Moscow (1986).

4. N. Valko, Electrodeposition of zinc alloys in the presence of x-ray radiation field, Izv. Vyssh. Uchebn. Zaved., Fiz., 57, No. 12, 87-90 (2014).

5. State Standard GOST 9.309-86. Plated Coatings. Determination of the Sputtering Capacity of Electrolytes in Production of Coatings. Introduced on 21.01.1986, Gosstandart, Minsk (1986).

6. State Standard GOST 9.308-85. A Single System of Protection from Corrosion and Ageing. Metallic and Nonmetallic Inorganic Coatings. Methods of Accelerated Corrosion Tests. Introduced on 01.01.1987.

7. N. Batura, On the information content of the results of measurements, J. Eng. Phys. Thermophys., 89, No. 2, 506-513 (2016).

8. Yu. P. Adler, E. V. Markova, and Yu. V. Granovskii, Planning Experiment in Searching for Optimal Conditions [in Russian], Nauka, Moscow (1976).

9. A. Zakheim, Introduction to Modeling Chemical-Technological Processes [Russian translation], Khimiya, Moscow (1982).

10. V. Prokhorov, Optimizing Methods for Solving Technological Problems [in Russian], Yuzhno-Ross. Gos. Univ. Ékon. Servisa (YuRGUÉS), Shakhty (2004). 